\title{
An investigation on Kangan gas refinery wastewater
}

\author{
${ }^{1}$ S. M. T. Sadatipour, ${ }^{* 1}$ L. Mirzaie and ${ }^{2}$ A. A. Rezaei \\ ${ }^{I}$ Department of Marine Science and Technology, Islamic Azad University, Tehran North Branch, Tehran, Iran \\ ${ }^{2}$ National Iranian Gas Company, Research and Development Division, Tehran, Iran
}

\begin{abstract}
Kangan Gas Refinery is one of the greatest gas refineries in Iran. Environmental affects of this refinery should be assessed because of its high economic importance, as well as its considerable revenue. Since the gas refinery is classified in highly polluted industry, therefore the impact of wastewater the refinery should be determined. This research is carried out on March 2002 at Kangan refinery, which is located in Kangan city, southern part of Iran. The gas refinery wastewater generally includes oil, hydrocarbon materials and chemical additives, which are in the form of emulsion in water. The following parameters, such as oil and grease, PAHs, $\mathrm{BOD}, \mathrm{TH}$, turbidity, $\mathrm{COD}, \mathrm{EC}, \mathrm{pH}, \mathrm{TSS}, \mathrm{SiO}_{2}, \mathrm{PO}_{4}$ are determined in wastewater of the refinery in order to determine the amount of pollutants, which are affecting the area where the refinery is located. The oil and grease are analyzed by FTIR and PAHs are determined by UV-Luminance and physico-chemical parameters are determined according to the Standard Methods. The results show that although pollution of the refinery wastewater is within world permissible limits (EPA), but since the area is affected by the wastewater and surrounding area is confined with river basin it could be concluded that pollutants, which are discharged to the echo environment, are not in the permissible limits of the similar Industries.
\end{abstract}

Keyword: PAHs, oil and grease, physical and chemical parameters, refinery wastewater

*Corresponding Author, E-mail: rozitaco@yahoo.com

\section{Introduction}

It is quite clear that air, water and soil are among vital elements of the life on earth (Rose, 1998). During certain period in the past, human being and other living animals enjoyed clear and clean water and air, but industrial revolution during $19^{\text {th. }}$ century and its perfection in $20^{\text {th. }}$ century, gradually caused air, water and soil to become polluted. Nowadays, environmental pollution has already reached to a certain scale that it threatens and endangers the health of human beings and survival of other living things. For the same reason, most countries especially industrial countries have taken certain fundamental measures for the prevention of environment pollution (Esmaili sari, 2003). At present among the most crucial surface water sources used by human during past centuries. Rivers are the valuable echo- system, besides playing a crucial role in providing great portion of water demanded for agriculture, industry and drinking water, are also considered vital, social, economical problems in different societies (Jenkins, 2001). The environment around us should be exploited in such a way both to provide our reasonable daily needs and at the same time not to be confronted by damage, loss or intimidation by our side. Otherwise in long-term and sometimes short- term, the damage will not only affect us, but also will damage our future. Based on above said, this research is carried out to determine environmental impact of Kangan refinery wastewater around and proposing the refinery various ways of controlling the pollutants.

\section{Materials and Methods}

This work is carried out in 12 March 2002 at Kangan refinery, which is located in Kangan city at the southern part of Iran.

Based on the research work carried out by various environmental scientists such as Larson, 1994, Dclaun, et al., 1980, Cerniglia and Heitkamp, 1989, Neff, 1984 and Neff, 1974. Twelve samples are collected and analyzed from different stations, which are given in Figure 1. Station 1. Surface wastage 1, between phases 1 and 2 (units 2,100-2,200) 
- Station 2. Surface wastage 2, opposite steam unit phase 2, (9200)

- Station 3. Purified biological wastage and washed up wastage in side the workshop and the surrounding area.

- Station 4. Oil reservoir

- Station 5. Lagoon entrance

- Station 6. Drying pool No.1

- Station 7. Drying pool No. 4

- Station 8. Drying pool No. 7

- Station 9. Spillway of drying pool

- Station 10. Burning well Spillway

- Station 11. Car wash

- Station 12. Garage

\section{Oil reservoir}

Separating system of water and oil (oil filter) has been installed in order to separate oil and waste solid materials such as, wood, plastic, etc. to obtain purified water. Oil filter includes a metal disc, which filters all kinds of rubbik and other solid materials. Other parts of polypropylene oil filter, which absorbs oil. The remaining water and oil enters the lagoon.

\section{Burning well}

When oil is gathered in oil reservoirs, it is permitted to the burning well and is burnt. (In fact, liquid non-standard hydrocarbons in the form of dried material or moisture are gathered from all parts of refinery and are burnt far from that place).

\section{Drying pool system}

In order to dry the saline water, certain drying pool has been provided.

\section{Lagoon}

It is in the shape of a reservoir of which the walls and bedding are made by rubber to prevent oil absorption (NIGC, 1992). Dark glass pots are used for sampling. After that they were washed with detergent, then with distilled water, and finally have been dried. The next phase is to choose certain pots for measuring oil and grease. They are washed with $\mathrm{C}_{2} \mathrm{~F}_{3} \mathrm{Cl}_{3}$. Other pots for measuring PAHs are washed with solution mixture (30\% dychloromethan and $70 \%$ normal hegzan). One liter of each sample was taken with similar condition. In order to stabilize oil and grease was added $50 \mathrm{ml} .\left(\mathrm{C}_{2} \mathrm{~F}_{3} \mathrm{Cl}_{3}\right) 2.5 \mathrm{ml}$. sulphoric acid and 5 gram salt. In order to stabilize combination of polycyclic aromatic $25 \mathrm{ml}$ solution mixtures were added and finally the samples are kept in refrigeration at 4 degrees centigrade (ASTM, 1982 and (ROPME, 1982).

\section{Petroleum, grease and polycyclic aromatic hydrocarbons determination}

FTIR and spectrometric florescence ultra violet were used to measure oil and PAHs pollution in water samples. This method has got certain advantages, which are showed, in following pathway.

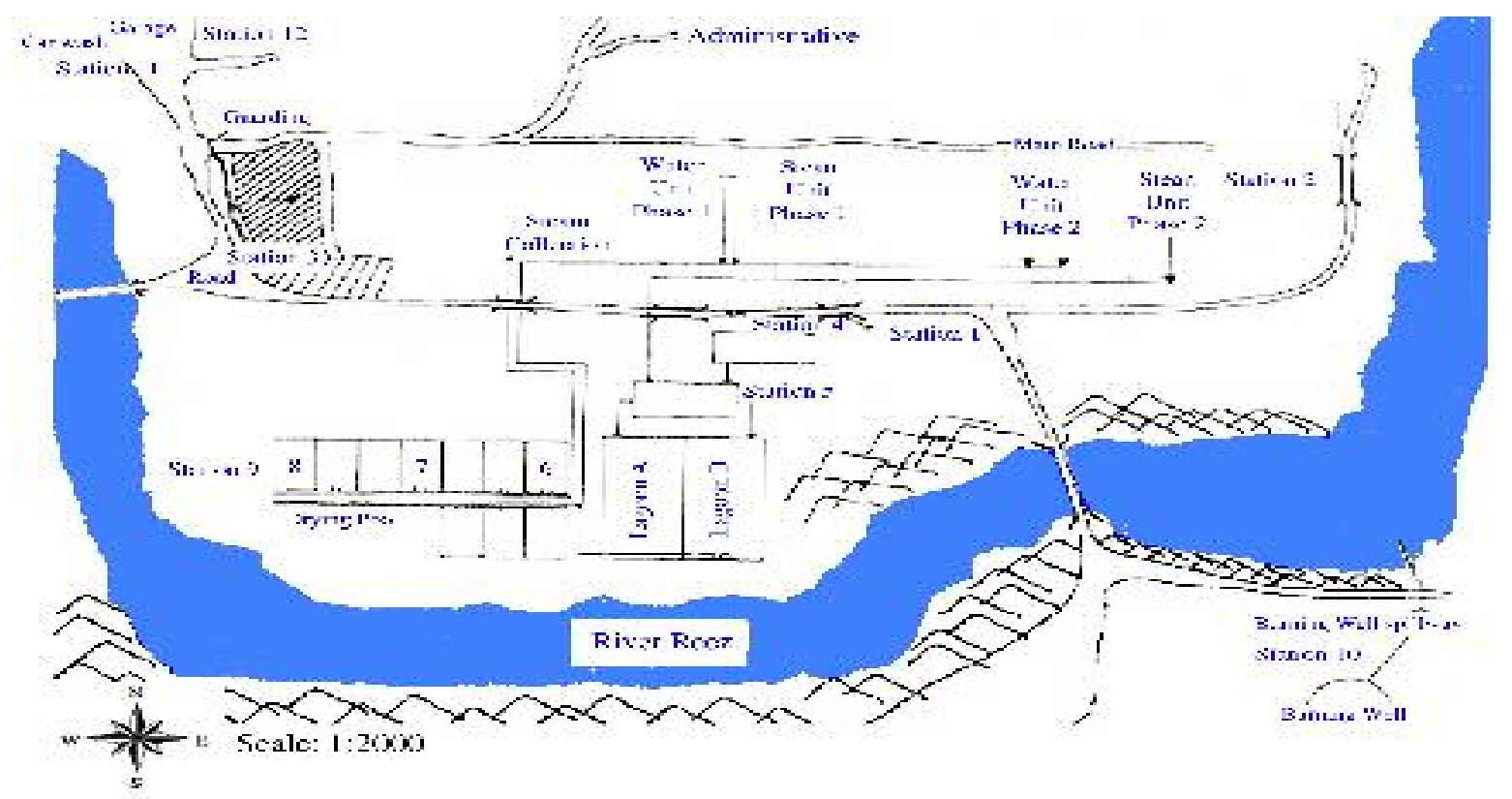

Figure 1: Sampling locations 
1. Pathway for oil and grease in water sampling (Table 1)

Stabilization and preservation of water samples by $\mathrm{H}_{2} \mathrm{SO}_{4}, \mathrm{NaCl}\left(\mathrm{CCl}_{4}\right)$ or $\mathrm{C}_{2} \mathrm{~F}_{3} \mathrm{Cl}_{3}$

Shaking the samples for 15 minutes in the laboratory (by shaker)

First phase separation through funnel

Filtration and moisture deleting by sodium sulphate

Reading absorption rate of hydrocarbon in the extract samples by FTIR

Measuring the density using standard deviation

2. Pathway for PAHs in water sampling (Table 2)

Stabilization and protection at site by solution

Shaking the samples for 15 minutes in the laboratory

Separation solution through a funnel

Filtration and moisture deletion with sodium sulphate

Reading absorption rate of PAHs in the extract samples by luminescence spectrometer

Measuring the density using standard deviation

Determination of physical-chemical parameters

Besides determination of petroleum, grease and polycyclic aromatic components, different parameters such as EC, turbidity, hardness, $\mathrm{SiO}_{2}$, phosphate, COD, BOD, $\mathrm{pH}$, chloride, TSS are determined (Table 3 ).

\section{Results}

The results show that although the rate of oil and grease are in permissible limits $(10 \mathrm{mg} / \mathrm{l})$ base on standard given for gas refinery (EPA, 2002) but because this waste water do not remain at the refinery and enters to the surrounding environment especially at stations $1,2,3,9,10,11$, and 12. Therefore the echo environmental balances in this region are disturbed and said pollutants has left high amount of damage. Thus, controlling and purification of the refinery wastewater as suggested here is so important and must be taken into consideration.

Table 1: Analysis of oil determination

\begin{tabular}{|cc|}
\hline Stations & $\begin{array}{c}\text { Oil in water } \\
(\mu / \mathrm{l})\end{array}$ \\
\hline Station No.1 & 1.2 \\
\hline Station No.2 & 4.9 \\
\hline Station No.3 & 0.6 \\
\hline Station No.4 & 26 \\
\hline Station No.5 & 13.4 \\
\hline Station No.6 & 11.5 \\
\hline Station No.7 & 8.6 \\
\hline Station No.8 & 6.5 \\
\hline Station No.9 & 1.1 \\
\hline Station No.10 & 5.8 \\
\hline Station No.11 & 7.5 \\
\hline Station No.12 & 2 \\
\hline
\end{tabular}

Table 2: results of $\mathrm{PAH}_{\mathrm{S}}$

\begin{tabular}{|cc|}
\hline Stations & PAHs $(\mu / \mathrm{l})$ \\
\hline Station No.3 & 0.93 \\
\hline Station No.5 & 18.5 \\
\hline Station No.8 & 0.25 \\
\hline Station No.9 & 0.25 \\
\hline Station No.10 & 7.1 \\
\hline Station No.11 & 0.25 \\
\hline
\end{tabular}

\section{Discussion and Conclusion}

From analyses of samples taken and compare with world permissible limits (Table 4) the following conclusions could be drived:

1. Stations 1, 2 (surface wastewater 1-2) oil and grease in these stations due to washing yards, rainfall, runoff, surface washing and equipment washed.

2. Station 3. Pollution due to wastewater of biological purification, washing of workshop and cleaning of the surrounding area. 
Table 3: Analysis of physico - chemical parameters

\begin{tabular}{|ccccccccccc|}
\hline Stations & $\mathrm{NTU}$ & $\begin{array}{c}\mathrm{Cl} \\
(\mathrm{mg} / \mathrm{l})\end{array}$ & $\begin{array}{c}\mathrm{COD} \\
(\mathrm{mg} / \mathrm{l})\end{array}$ & $\begin{array}{c}\mathrm{BOD} \\
(\mathrm{mg} / \mathrm{l})\end{array}$ & $\begin{array}{c}\mathrm{PO}_{4} \\
(\mathrm{mg} / \mathrm{l})\end{array}$ & $\begin{array}{c}\mathrm{SiO}_{2} \\
(\mathrm{mg} / \mathrm{l})\end{array}$ & $\begin{array}{c}\mathrm{TSS} \\
(\mathrm{mg} / \mathrm{l})\end{array}$ & $\begin{array}{c}\text { Hardness } \\
(\mathrm{mg} / \mathrm{l})\end{array}$ & $\begin{array}{c}\text { Electrical } \\
\text { conductivity } \\
\mathrm{ms} / \mathrm{cm}\end{array}$ & $\mathrm{pH}$ \\
\hline $\begin{array}{c}\text { Station } \\
\text { No.1 }\end{array}$ & 30 & 15 & 640 & 145 & 2.1 & 2.1 & 20 & 38 & 510 & 10.1 \\
\hline $\begin{array}{c}\text { Station } \\
\text { No.2 }\end{array}$ & 5.5 & 390 & 50 & 20 & 0.04 & 9.6 & 10 & 230 & 2,160 & 8.3 \\
\hline $\begin{array}{c}\text { Station } \\
\text { No.3 }\end{array}$ & 8.5 & 520 & 70 & 30 & 15.4 & 6.4 & 20 & 94 & 5,400 & 9.8 \\
\hline $\begin{array}{c}\text { Station } \\
\text { No.5 }\end{array}$ & 35 & 85 & 3,840 & 750 & 0.012 & 1.1 & 10 & 90 & 1,320 & 8 \\
\hline $\begin{array}{c}\text { Station } \\
\text { No.9 }\end{array}$ & 45 & 4,700 & 680 & 350 & 0.4 & 8 & 300 & 1,480 & 15,600 & 7.8 \\
\hline $\begin{array}{c}\text { Station } \\
\text { No.10 }\end{array}$ & 38 & 1,410 & 4,160 & 2,000 & 0.07 & 18 & 55 & 190 & 8,100 \\
\hline
\end{tabular}

Table 4: World permissible limits (EPA) specified for oil and grease (mg/l)

\begin{tabular}{|cccccccc|}
\hline $\begin{array}{c}\text { Site of } \\
\text { samples }\end{array}$ & $\begin{array}{c}\text { Surface } \\
\text { water }\end{array}$ & $\begin{array}{c}\text { Absorbed } \\
\text { wells }\end{array}$ & $\begin{array}{c}\text { Agricultural } \\
\text { water }\end{array}$ & $\begin{array}{c}\text { Drinking } \\
\text { water }\end{array}$ & Rivers & $\begin{array}{c}\text { Waste } \\
\text { water }\end{array}$ & $\begin{array}{c}\text { Sea } \\
\text { water }\end{array}$ \\
\hline $\begin{array}{c}\text { oil and } \\
\text { grease }(\mathrm{mg} / \mathrm{l})\end{array}$ & 10 & 10 & 10 & 0.5 & 0.5 & 10 & 0.1 \\
\hline
\end{tabular}

Table 5: World permissible limit (EPA) for $\mathrm{PAH}_{\mathrm{S}}$ in water

\begin{tabular}{|ccccc|}
\hline $\begin{array}{c}\text { Sampling } \\
\text { site }\end{array}$ & $\begin{array}{c}\text { Underground } \\
\text { water }\end{array}$ & $\begin{array}{c}\text { Surface water } \\
\text { with small of pollution }\end{array}$ & Polluted surface water & Wastewater \\
\hline PAHs (ng/l) & $10-50$ & $50-250$ & up to 1,000 & 100,000 \\
\hline
\end{tabular}

3. The amount of oil and grease are decreases from the reservoir (station 4) to lagoon (station 5) by separation system. From station 6 to 9 (last spillway) the amount of pollution decrease because of its absorption by mud.

4. Station 10 (burning well spillway). This oil is gathered in the reservoir and is transferred to the burning well. As a matter of fact the non-standard excess liquid hydrocarbons in dry and wet shape mixed with water are collected in the refinery and burnt in the well. Thus the spillway liquid is highly polluted.

5. Station 11 (car wash) and station 12 (garage). A large amount of oil and grease due to washing the motors and repayments are gathered there.

6. In winter a large amount of oil pollution is due to decrease in evaporation and temperature, low activity of microorganism and biological demolition.

7. The PAHs concentration in all the sampling stations is in the permissible limits (Table 5) except in the burning well spill way.

8. In Station 3. The pollution is due to wastewater after biological treatment, surface washing and workshop clean up.

9. In station 11 (carwash), the presence of PAHs is due to oil and grease pollutants in carwash and machinery washing yard sewage.

10. In the Station 10 (burning well spill way). PAHs concentration is due to semi burning of organic material, which is enterers, the river.

11. Station 5 (lagoon entrance) PAHs are because of wastewater mixed with oil product. This wastage after the lagoon is pumped to drying pool. Finally the flow reduces at station 8 (seventh drying pool) and station 9 (spillway of seventh drying pool). 
This trend of reduction is because of:

- The effect of UV, from sunshine, which plays an important role in PAHs analysis, because PAHs is a good absorption of ultra violet rays.

- Agitated form of Oxygen molecule (02) created by sunlight, which is an important element in breaking PAHs on water surface.

- Low solution of PAHs in water.

- Having dehydration quality.

- Due to having aromatic quality, these components stick to Materials and small solid and subsequently reside under water.

12. In all the station we can point out, since air is so polluted in gas refineries, air mass in such regions reserves PAHs components in themselves. During rainy season, these particles are washed away and enter water.

From all outlet points to the river, Physical-Chemical parameters such as, $\mathrm{pH}, \mathrm{EC}$, Hardness, TSS, $\mathrm{SiO}_{2}, \mathrm{PO}_{4}$, BOD, Turbidity, COD and Chloride were determined.

13. Station 1. All parameters were measured and they are all according to permissible limit except BOD, COD, The reason is washing the surface and cleaning the equipments. Dust and residing soil in the area of refinery due to rainfall enters surface canals and finally in to the river containing organic and mineral materials.

14. At this station the hardness is high because of pipe corrosion all the wastage of electrolysis and zeolit units are entering at this point.

15. Station 3. At this point $\mathrm{pH}$, phosphate and COD is higher than normal limits it can be due to biological purification, workshop, washing yard, surface wastewater, mineral and organic, material such as detergents are used.

16. Station 5 (lagoon entrance) high levels of BOD and COD at this point can be due to high level of refinery wastewater including organic and mineral material.
17. Station 9. Majority of parameters are higher than permitted level the reason is as follows:

Salty water at high level enters drying pool, level of hardness; chloride at the spillway of eighth station is higher than standard level.

18. Station 10 (burning well spill way). At this point similar to point 9. Parameters are higher than permissible limit because nonstandard hydrocarbon liquid is gathered and burnt.

19. BOD and COD decrease from entrance of the lagoon to the last station because of increase in wind blowing rate. At the same time the hardness, EC and Ions are increase because of salty water. High level of silica is because of dust entered at this station.

20. Based on the results obtained. It can be conclude that the spillway in the burning well and the seventh drying pool is the most polluted area.

With refer to the above results and conclusion the flowing suggestions are derived.

1. Station 3, is near biological purification unit and this system at present is working more than its capacity and must be upgraded in this regard.

2. Due to high level of pollution at stations 4, 5, 6, 7, 8 and 9 it seems that the reservoir, the lagoon and drying pools are old and have worked since inauguration of the refinery, they can not control the increasing of the oil, grease and PAHs monitoring should be carried out for wastewater before and after entering the river.

3. Due to certain issues, some sections belong to recycling water has not yet been started, therefore starting to develop these sections also regarded important in future.

4. Protection, of mechanical conditions, all tools equipment, machinery and precise tools is so necessary using the best 


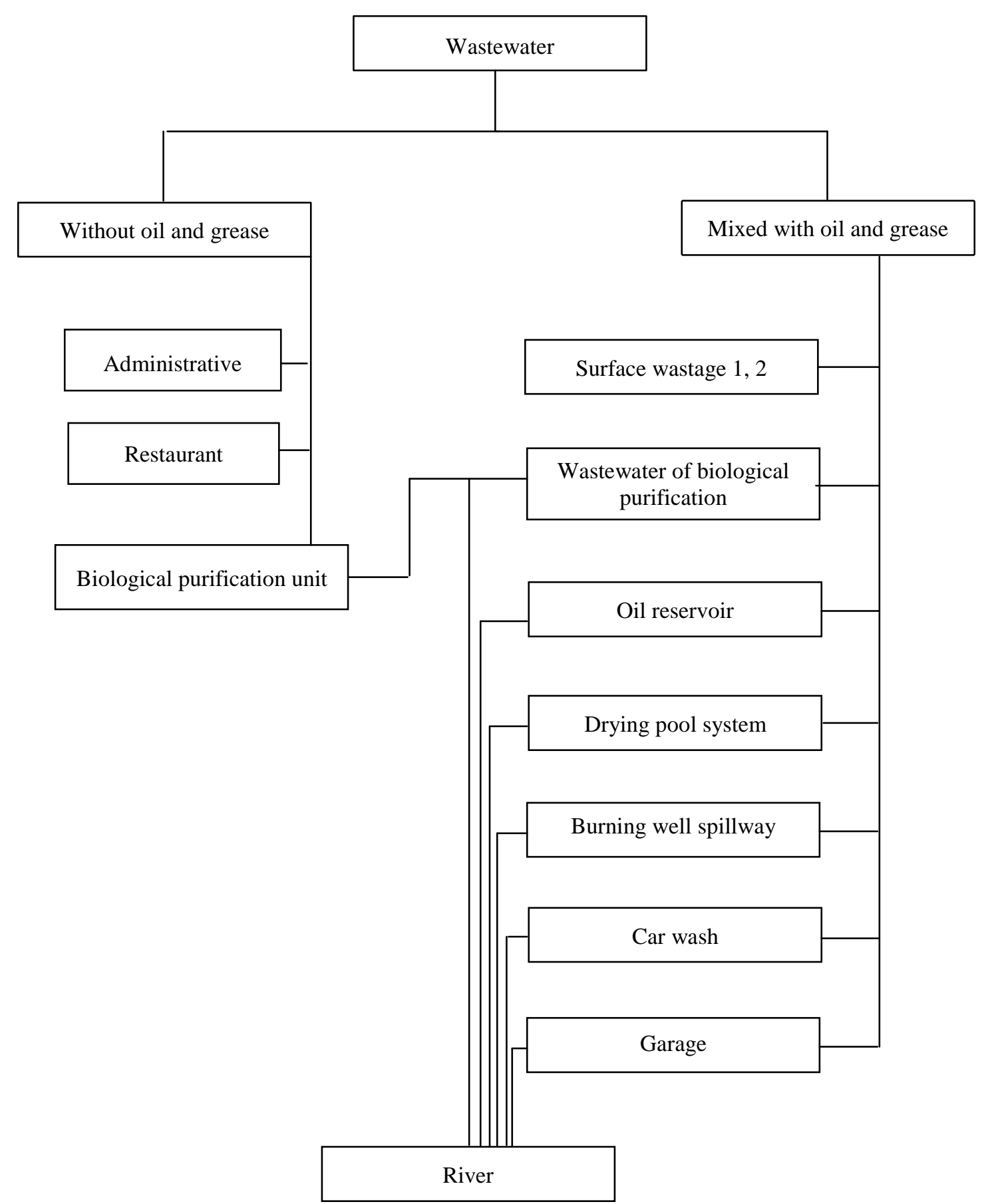

Figure 2: Refinery present condition

facilities and training courses for the workers of the refinery.

Measures should be taken not to pollute the environment of the refinery and prevent from pouring oil products and chemical material in working environment to decrease the level of pollution.

5. It is recommended to construct a reservoir so that microorganisms analyze chemical materials.
6. Reservoir with fine sand about 45 to 64 microns can be convertible to absorb the oil from wastewater. All wastewater outlets should be collected through on pipeline. Pouring wastewaters should be done according to standards. Observing these standards must be based on environmental resolutions.

7. Detecting corrosions must be carried out regularly to protect pipe corrosion. 


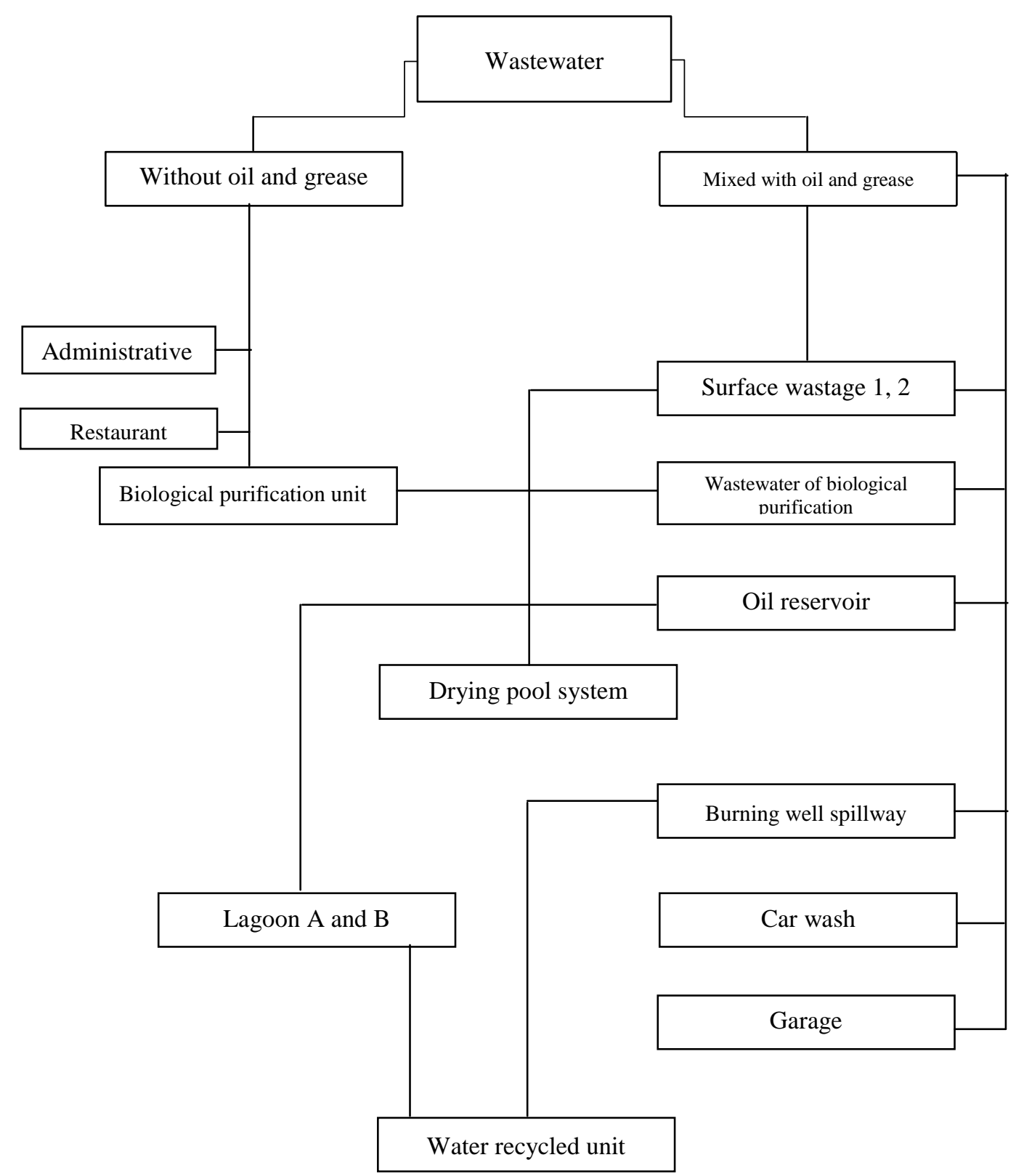

Figure 3: Refinery designed condition

Some level of pollution is because of this defect.

8. To prevent spilling wastewater into the environment, level of the spillway, should be increased, other wise due to increasing the production level, one should be installed.

9. To regulate and prevent wastage from the spillway certain reservoir with suitable gradient and their filtering system should be installed in place.

10. The pollution control should be carried out base on flow chart given at present, designed and proposed condition (Figures 2, 3 and 4).

\section{Acknowledgements}

The authors are indebted to various individuals and organizations that have contributed to this research. They are very grateful to these who are as follows for their major contributions and kindly corporate:

The Islamic Azad University, Department of Marine Science and Technology faculty members, The Research and Development, Staff members of National Iranian Gas Company and finally Dr. J. Nouri for his great help and support who gave generously his time and information toward this study. 


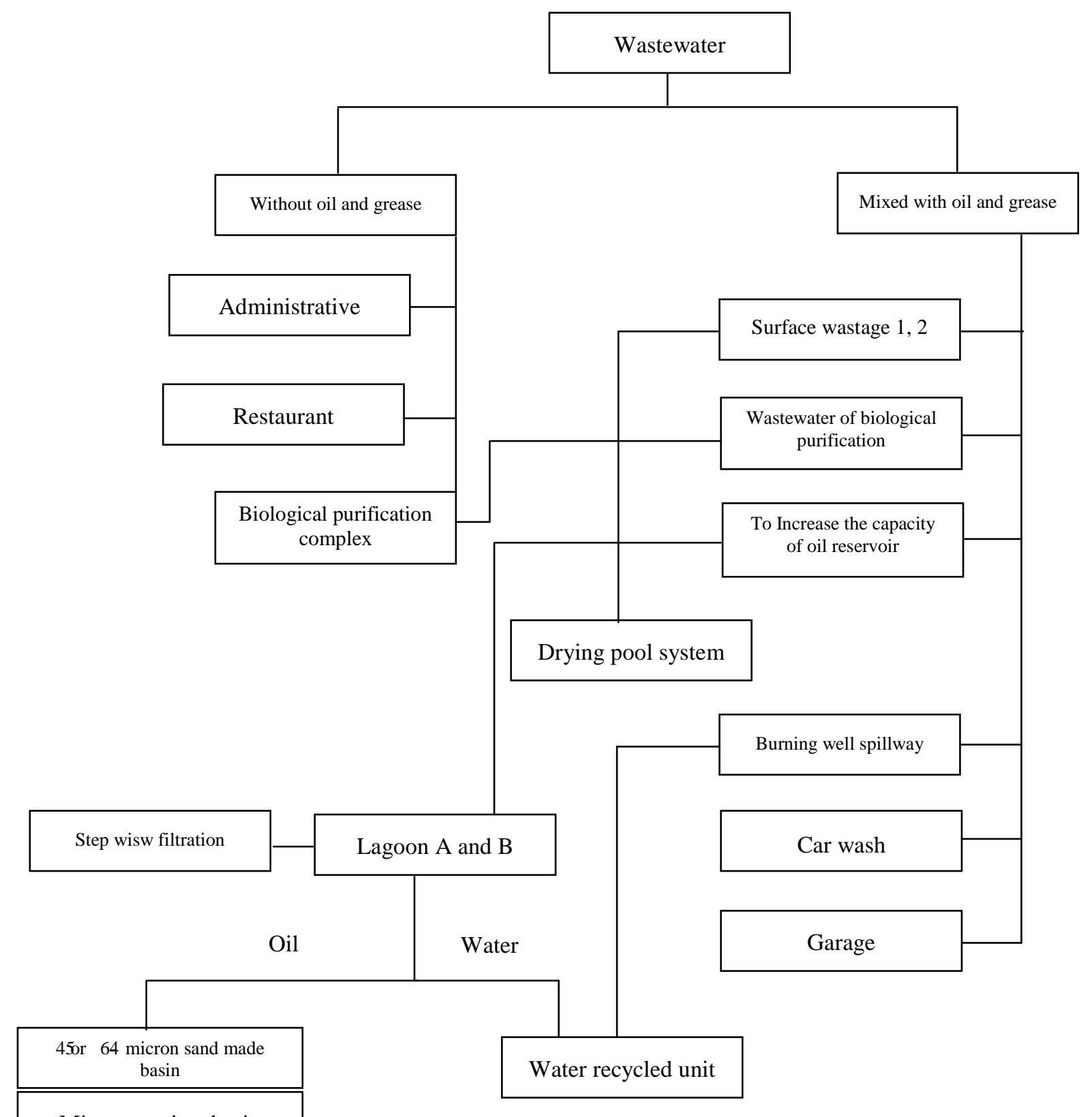

Figure 4: Refinery proposed condition

\section{References}

American society for testing and material (ASTM), Annual Book of ASTM standards. Part 31: 180 1982

Cerniglia C. E. and M. A. Heitkamp, Microbial degradation of $P A H$ in the aquatic environment, in metabolism of polycyclic aromatic hydrocarbons in the aquatic environment, variance, CRC. Press, Boca Raton, FL., 41, 1989

Dclaun, R. D., G. A. Hambrick, and W. K. Jr Patrick, Degradation of hydrocarbons in oxidized and reduced sediments, Mar. Pollut. Bull: 11 103, 1980

Environmental Protection Agency, (EPA/623/R/ 002S), USA, 2002

available at:

http://www.epa.gov

Esmaili Sari, A., Pollution, health and environmental standards, NaghsheMehr publication, 2003 
Jenkins, S. H., Water quality management, Pergamon Press, NewYork, 2001

Larson, R. A. and E. J. Weber, Reaction mechanisms in environmental organic chemistry, CRC Press, 1994

National Iranian Gas Company report (NIGC/R/ 195002Q,), 1992

available at:

http://www.nigc.com

Neff, J. M., Polycyclie aromatic hydrocarbons in aquatic environment; Source, fates, and biological effects. Applied science, London, 1974
Neff, J. M., Polycyclic aromatic hydrocarbons. In fundamentals of aquatic toxicology, Rand G. M. and petrecedllo, S. R. (Ed.), Hemisphere, New York, 416, 1985

Regional organization for the protection of the Marine environment (ROPME), Manual of oceanographic observation and pollutant analysis methods (1-7): 220-226,1982

Rose, J. Water and the environment. Gordn and Breach Science Publishers, Philadelphia, USA, 1-15, 1998 
